\title{
The Narratology of Fictional Utterances in Adrakha Al-nassian
}

\author{
Samana Musapour \\ alsariyh.moosapoor@yahoo.com
}

$\mathrm{PhD}$ Student in Arabic Language and Literature, Islamic Azad University, Karaj, Iran. (Coresponding Author).

\section{Youssef Hadi pour $\quad$ hadi9331@yahoo.com}

Assistant Professor and Faculty Member at the department of Arabic Language and Literature, Islamic Azad University, Karaj, Iran.

\begin{abstract}
One of the important elements in the story is the utterances of fictional characters as they illuminate the words, thoughts, and personality of the characters. Utterances are conveyed to readers via narrators, which is subsumed under the rubric of "narrative style" that determines the relationship between the narrator and characters. Adrakha Alnassian, a realistic novel by the contemporary Jordanian writer Sanaa Al-Shalan, has taken advantage of narrative techniques in relation to characters and events and draws on the five narrative methods in order to depict political atmosphere in Syria. The objective of this descriptive-analytical study is to determine the extent to which Shalaan uses each of these methods in different fictional contexts, as each is used for a specific purpose on behalf the writer. It is observed that the use of narrative methods starts with the dominance of the narrator in the story and ends with the complete domination of characters. Narrative report is often used in the case of observing brevity and avoiding detailed descriptions of events while direct utterance is used in order to explain the psychological and cognitive dimension of characters, depicting their inner feelings in dealing with social realities.
\end{abstract}

Keywords: Narrative methods, Fictional Narratives, Sanaa Al-Shaalan, the contemporary Arabic novel, "Adrakha Al-nesyan".

Citation: Musapour, Samana; Hadi pour,Youssef. Spring and Summer (2021). Narrative style "Fictional Narratives" in the novel "Perceptions of "Adrakha Al-nesyan". Studies in Arabic Narratology, 2(4), 168-185. (In Arabic)

Studies in Arabic Narratology, Spring and Summer (2021), Vol. 2, No.4, pp. 168-185.

Received: July18, 2021 Accepted: October17, 2021

(C)Faculty of Literature \& Humanities, University of Kharazmi and Iranian Association of Arabic Language \& Literature. 


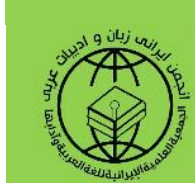

دراسات في السردانية العربية

الرقم الدولي الموحد للطباعة: • rTVT-VV

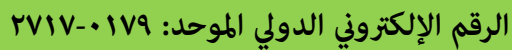

\section{أسلوب سرد „الأقوال الروائية) في رواية»أدركها النسيان/ لسناء الشعلان}

alsariyh.moosapoor@yahoo.com البريد الإلكتروني:

سمانه موسى يور

طالبة دكتوراه في اللغة العربية وآدابها، جامعة آزاد الإسلامية، كرج، إيران. (الكاتبة المسؤولة) hadi9331@yahoo.com

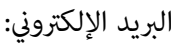
يوسف هادي بور أستاذ مساعد بقسم اللغة العربية وآدابها، جامعة آزاد الإسلامية، كرج، إيران.

الإحالة: موسى بور، سمانه؛ هادي بور، يوسف. ربيع وصيف (الr.r). أسلوب سرد (الأقوال

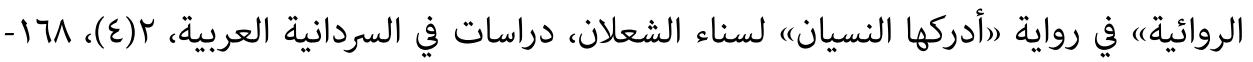

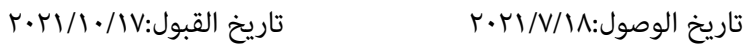

ه كلية الآداب والعلوم الإنسانية بجامعة الخوارزمي والجمعية العلمية الإيرانية للغة العربية وآدابها.

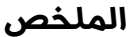

تعتبر "أقوال" الشخصيات إحدى العناصر المهمة في القصة. لأنها تكشف كلمات وأفكار وأرواح الشخصيات. كيفية نقل الأقوال من الكاتب إلى القارئ تتم من خلال "الراوي" وتذكر تحت عنوان "أساليب سرد الأقوال الروائية" التي تتشكل على أساس علاقة الراوي بالشخصيات. إن الرواية الشهيرة الواقعية "أدركها النسيان " للكاتبة 
الأردنية المعاصرة سناء الشعلان هي واحدة من تلك الروايات التي استطاعت استخدام الحيل السردية المناسبة للشخصية والواقع، واستطاعت أن تستخدم الأساليب السردية الخمسة في نقل الروايات السردية لتصويرالمناخين السياسي والاجتماعي الذي يحكم على المجتمع السوري. الغرض من هذه الدراسة الوصفية التحليلية هو تحديد مدى استخدام كل من هذه الطرق في المواقف المختلفة. تم استخدام كل من هذه الطرق

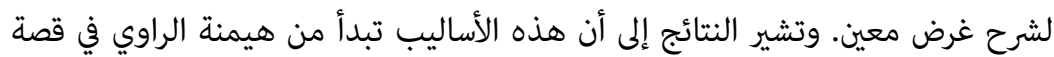
التقرير السردي وتنتهي بالسيطرة الكاملة للشخصية في القصة (الطريقة الحرة المباشرة)غالبًا ما يتم استخدام التقرير السردي في حالات مثل مراقبة الإيجاز وتجنب الأوصاف التفصيلية للأحداث، وقد تم استخدام الكلام المباشر أكثر في شرح البعد ماتبه النفسي والمعرفي للشخصيات وتصوير مشاعرهم الداخلية في التعامل مع حقائق

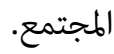
الكلمات المفتاحية: الأساليب السردية، الأقوال الروائية، سناءالشعلان،

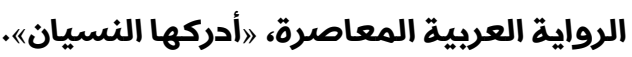

لكلمة السرد، في قواميس معجمية مختلفة، معان مختلفة مثل؛ القصص والأوصاف

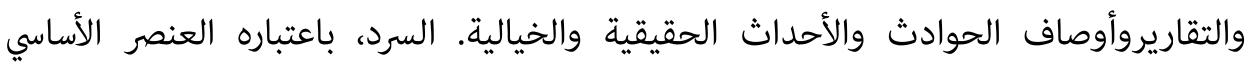
والنوع الأدبي المتفوق، هو "الشكل" الذي يشكل السرد المركزي وروايات القصة الأخرى

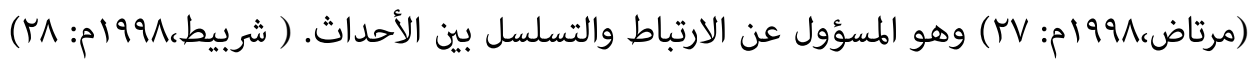
والقناة لنقل اساس الرواية من الروائي، المؤلف (الفاعل الكاتب) للمتلقي (الفاعل القارىء). (الحمدانى، الهوام:09ع).معتبرا أن شكل وطريقة نقل السرد مهم جدا بالمقارنة مع الموضوع. في النقد الحديث، يتم اكتشاف الههام والتطبيقات والدوافع والفضاء والمنظور وما إلى ذلك من 
خلال النقد السردي القائم على تحليل النص ووصف الهياكل الجديدة، ولا مكان لسلطته

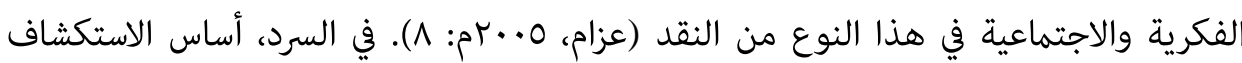
الروائي ومعيار تقويم نص أدبي للغة جديدة هو شكله وطريقة تعبيره، وموضوع القصة ليس هن معيار التقييم لأن فن الروائي يكمن في شكله التعبيري.إن الراوي يعد أحد من العناصر الرئيسية

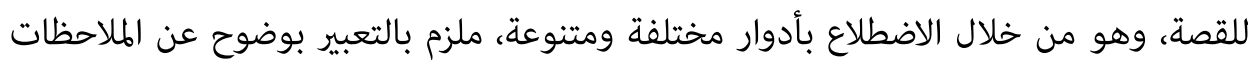

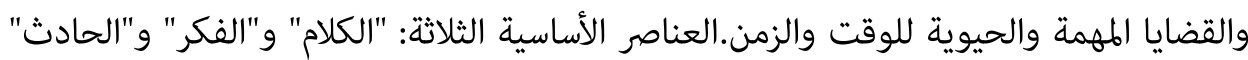

في السرد، ينقلها الراوي إلى القارئ بلغة السرد، في شكل شبكة متشابكة من العناصر السردية. " الكلام " من أكبر أجزاء القصة ومن خلال لعب الأدوار الرئيسية للغة الشخصيات الروائية، بأشكال مختلفة منها مباشر أو غير مباشر وتكون فعالة في تقدم السرد. منذ أن تم تأمين الرواية الواقعية "أدركها النسيان" من قبل علماء السرد على الرغم من الانعكاس المهم للغاية للقضايا السياسية والاجتماعية، وهذا جعل ضرورة مثل هذا البحث من قبل الكتاب أكثر وأكثر وضوحا. تحليلات الروائيين الأردنيين المعاصرين للإجابة على ما يلي أسئلة: ما هي الأساليب السردية المستخدمة في هذه الرواية الأكثر تكرارا وما هي أسباب

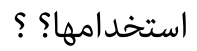
كيف قدم الراوي أبعاد شخصيات وأحداث رواية " أدركها النسيان" في عبارات سردية

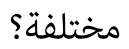

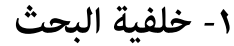

تم إجراء الكثير من الأبحاث حول أعمال "سناء الشعلان" باللغات العربية والأجنبية. حصل

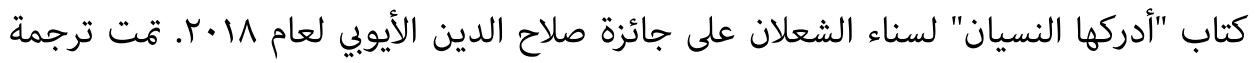
العديد من أعماله إلى الفرنسية والإنجليزية والهندية، إلخ. ومن أهم الأبحاث التي أجريت على الى

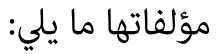
كتاب (رضائات التخليل مقاربات فى التشكيل والرؤى والدلالة فى ابداع سناء الشعلان القصصى")، وهو مجموعة من المواد التي جمعها "غنام محمد خضر". يحتوي هذا الكتاب على 
فضيلة قريب، في مقالتها بعنوان»الروية والتشكيل السردى في رواية (أدركها النسيان)، لسناء الشعلان انوذجاه التي بحثت في رواية(أدركها النسيان). سمانه موسى يور ويوسف هادي يور، لقد بحثا في مقالتهما (تطبيق الانطباعية في رواية (أدركها النسيان) لسناء الشعلان على أساس نظرية فيرجسون ) حول رواية (أدركها النسيان). https://san.khu.ac.ir/article-1-148-ar.html

( الراوي في القصص القصيرة الأردنية)، أطروحة صالح محمود فرحان الخزاعله (10 •rم) في كلية الآداب، الجامعة الهاشمية، الزرقاء، الأردن. في هذا العمل، بالإضافة إلى التعامل مع القصص القصيرة لكتاب أردنيين، فإنه يشير أيضًا إلى قصص سناء الشعلان.

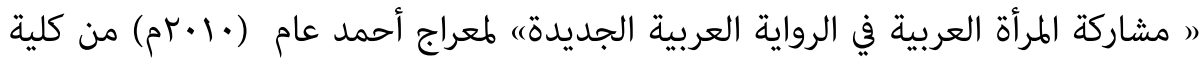
الآداب جامعة محمد أبو ضياف، الجزائر. يفحص المؤلف في هذا العمل مكان المكان كأحد عناصر القصة ويظهر فن سناء الشعلان في مجموعات قصصه. عناصر الاستدامة في مجموعة القصص(حدث ذات جدار) من سناء الشعلان من كتابة نعيم عمورى ومينا مجدم (وqبا ش) والتى تم نشرها في مجلة البحوث في تدريس اللغة العربية وآدابها. في هذا المقال، تناول المؤلفون مكونات الأدب الفلسطيني حول الاستقرار في المجموعة المذكورة واستكشفوا في هذا العمل قضايا مثل شجاعة المرأة، وتصوير الأعداء، والقلق والارتباك لدى أعداء التشرد الفلسطيني، إلخ. "تحليل رواية (السقوط فى الشمس) من سناء الشعلان على أساس نظرية تدفق السائل للعقل" من مرتضى زارع وفاطمه كاظمى (9 وبا ش) والتي تم نشرها فى المجلة الفصلية لسان مبين (بحث في الأدب العربي). في هذه المقالة، راجع المؤلفون المبادئ الأكثر وضوحًا لتدفق هريق العقل في الرواية، بما في ذلك سرد القصص، وتقنيات السرد، والزمان، والشعر. نظريات أخرى لبعض المفكرين والخبراء في التحليل والعلم والأدب كانت مؤلفات حول هذه الرواية، والتي عبرت عن نظرياتها في عدة صفحات، والتي يشار إليها بعدة نظريات أدناه: نشر سليم نجار نظريات حول رواية(أدركها النسيان) من سناء شعلان بعنوان (التجريبية في سرد (أَدْرَكهَا النّسيان) من"سناء الشعلان" ) ودرس هذه الرواية. 
سفيان صائب المعاضيدى بحث في رواية " التحليل النفسي" بحث في رواية (أدركها النّسيان) من الرواية سناء الشعلان)، عن رواية (أدركها النسيان). كما كتب عباس داخل حسن نيز مقالاً بعنوان( فقرات مبكرة من رواية(أدركها النسيان) من روسي

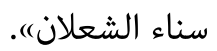

أظهر بحثنا أن رواية(أدركها النسيان) مل تتم مناقشتها في شكل مقال علمي مستقل، لذلك في هذه الخطوة الأولى نواجه دراسة جديدة. بالإضافة إلى ذلك، فإن الدراسة المتزامنة لأساليب السرد فعالة في ترسيخ ابتكار المقال الحالي.

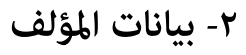
سناء كامل أحمد شعلان، كاتبة أردنية، ولدت عام 19VV في منطقة قديمة في مدينة صويلح ذات الغالبية العظمى من المهاجرين. أول كتاب حكاية قرأه وهو في سن الثالثة كان "دراجه عماد". أطلق عليها لاحقًا لقب "الكاتب الصغير". ولأنه كان لديها اهتمام خاص بالكتابة، فمنذ طفولتها أرسل قصصه إلى مجلة "وسام" الأردنية (عموري ومجدم، 99سا ش: 10)، وبدأت في مراجعة الكتب. كما أنها حاصلة على درجة الدكتوراه في الأدب الحديث وهى حاليًا أستاذة جامعية وعضو في جمعية الكتاب الأردنيين وجمعية الأدب العربي. ومن مجموعة أعمالها كتاب " تعليم اللغة العربية الناطقين بغيرها"، مجموعة قصصية "قافلة العطش"، " ناسك الصومعه"، " أرض الحكايه". و"السقوط في الشمس" و... (نفس المرجع: 10). في عام 1991، حصلت على درجة البكالوريوس في اللغة العربية وآدابها من جامعة اليرموك، ودرجة الماجستير في الأدب الحديث من الجامعة الأردنية عام ب..r، ودكتوراه في اللغة العربية من نفس الجامعة عام T7·r، مع مرتبة الشرف، بصفته عضو هيئة تدري بالجامعة الأردنية. (ويكيبيديا العربية)

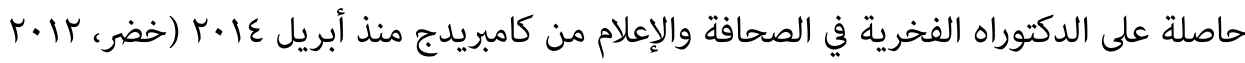

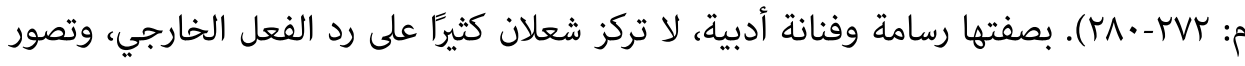
أحداث وأفكار ومشاعر شخصياتها بطريقة سلسة وغير مباشرة في روايته. تكشف الأشياء بعقل مقنع دون أي خوف ظاهر، ولا تختبئ وراء قناع لا يناسبه، وكأنها مواد أولية تستخدم في كل شيء، سواء كان فنيا أو خياليا. (موسى يور، ..عا: (1) حصلت سناء الشعلان على العديد من 
الجوائز عن تأليفها لهذه الكتب الروائية، من بينها جوائز " شرحبيل بن حسنه" و"أنجال هزاع آل نهيان في أدب الأطفال" و"دار ناجي نعمان". سناء الشعلان كاتبة ومفكرة معروفة، وشخصية ثقافية وأدبية عربية معاصرة نادرة، وناشطة في مجال حقوق الإنسان وحقوق المرأة وحقوق الطفل والعدالة الاجتماعية، وممثلة للعديد من المؤسسات الثقافية والحقوقية. وهى حاصلة على نجمة السلام العالمية وعضو في الجمعية الدولية لحقوق الإنسان. وهى عضو في معظم المعاهد البحثية والقانونية الأدبية والأكاديمية والإعلامية والمحلية والعربية والدولية، وتشارك في العديد من المشاريع الثقافية العربية والدولية. في أعمالها القيمة، حققت هذه المؤلفة مكانة بارزة في مختلف مجالات التاريخ والثقافة والأدب والفلسفة والتصوف، وكانت تعرف دائًا بأنها كاتبة صوفية وبإيديولوجيتها الصوفية. أعمالها، وخاصة العمل الروائي " أدركها النسيان"، بالإضافة إلى الجوانب الأدبية والاجتماعية واللاهوتية والأخلاقية، له موضوعات طويلة وجذور صوفية عميقة ومفاهيم دينية إسلامية تميزه عن غيره من الكتاب. حاصلة على حوالي سا جائزة دولية وعربية ومحلية في مجالات الرواية والقصة القصيرة وأدب الأطفال والطسرح. بالإضافة إلى ذلك، تم عرض العديد من مسرحياتها في المسارح المحلية والعربية. ترجمت أعمالها إلى العديد من اللغات مثل الإنجليزية والفرنسية والهندية والبريطانية وغيرها. تشكل أعمالها ومشاريعها الإبداعية أساسًا للعديد من دراسات البحث

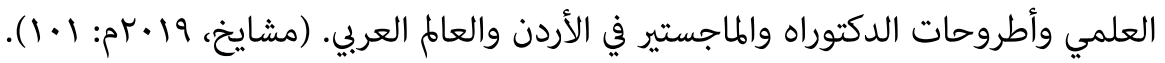

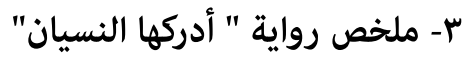

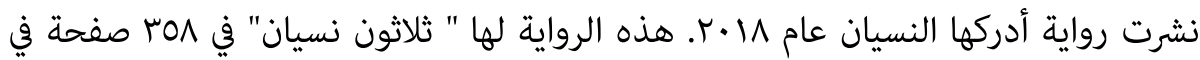
عمان ومطبوعات أمواج وهي الرواية الرابعة لشعلان وحازت على جائزة صلاح الدين الأيوبي. إن كتابة الرواية هي عبارة عن الحب والوطن واليتيم. يصور ضحاك وبهاء حياة طفلين يتيمين ومشردين في بلد في الشرق في دار للأيتام حيث ماتت جميع أسس الثقافة الإنسانية. تفشى الإيذاء الجسدي والتحرش الجنسي في دار الأيتام. الطفلان في خضم معاناة مدير ومعلم دار الأيتام. ضحاك متهم بالسرقة لأن والده كان ناشطا فلسطينيا سياسيا. في سجن سياسي، يُجبر على الاعتراف ويتعرض لتعذيب شديد من أجل الاعتراف بأنه مناضل سياسي. عندما كان طفلاً في 
العاشرة من عمره، يروي زورًا أسماء الأشخاص الذين بقى عذابهم دائًا في قلبه بسبب الأم والمعاناة من التعذيب. بعد اعتراف ضحاك لمدة عشر سنوات، جرده مسؤولو السجن من ملابسه

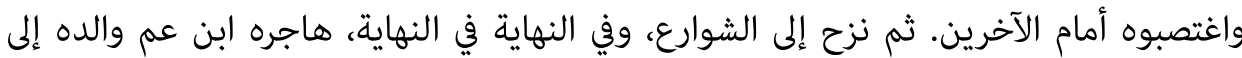
أرض جليدية باردة في شمال الدول الاسكندنافية. يحاول أن ينسى ما حدث في وطنه لكنه مل يستطع. وعد بإنقاذ بهاء، لكنه حاول مرات عديدة وفشل. انتظرت بهاء مرات عديدة أن يأتي بهت المنقذ ضحاك من شرفة دار الأيتام. فتى يتيم في تلك الأرض أصبح أستاذا جامعيا في مجال الأدب المقارن. كرس كل وقته للدراسات المقارنة والأدب الغربي المعاصر والعربي المعاصر. لكن الرواية لا تزال تحكي قصة البهائي، بطل الرواية. كان يعيش حياة صعبة، ففي سن الثامنة عشرة، بعد أن طُرد من دار للأيتام في حالة فقر، عاش حياة الدعارة والخط، ثم أصيب لاحقًا بسرطان الدماغ. بهاء تسعى للعثور على ضحاك. ضحاك، الذي أصبح روائيًا مشهورًا، يكتب اسم ضحاك بأحرف كبيرة على ظهر جميع أعماله؛ ربما رأت عشيقته الكتاب والاسم الذي أعطته للصبي في دار الأيتام. في السبعينيات، وجد الاثنان بعضهما البعض. تختفي ذكراهما مع لقاء الحبيب " ضحاك ". وتفقد ذاكرتها. قرر ضحاك أن يكون مع في هذا الوقت، وعندما يكون المرض في ذروته، يتغلغل السرطان بعمق في دماغهت ويدمر جسد بهاء. لا يزال يحب بهاء ذات ستين عاما. باربرا، سكرتيرة ضحاك، صبغت شعرها باللون الأحمر لتبدو مثل بهاء، لكنها مل تستطع محو حب بهاء من ضحاك. الرواية لها نهاية غامضة تدهش القارئ. أخيرًا، قرأنا أن اليتيمين كانا يعيشان في قبو دار الأيتام. ماتت فتاة حمراء ملعونة وصديقها جوعا ودفنا في القبو بعد أن حبسهما مدير دار الأيتام في القبو. ظهر الاثنان كأنها شبح أمام الأطفال. هذه قصة أيتام وأطفال الشوارع المهمشين في وطنهم. القارئ بطريقة ما منخرط عقليًا في الافتراضات المحتملة للرواية. ربما كان الأشباح هم الطفلان بهاء وضحاك في قبو الملجأ. ع- أساليب سرد "الأقوال السردية" في رواية " أدركها النسيان" الرواية تنتقل الراوي القصة إلى الجمهور بطرق مختلفة (ستار، ب.. ب م: 70). وبالطبع فإن تنوع أساليب السرد هو نتيجة التفكير والتأمل والاختلاف في أهداف القصة، ولا يشير إلى تفوق رواية على أخرى، بل على انسجامها مع "هدف" الراوي. يجب أن يعرف المحلل طريقة سرد 
الرواية من أجل تحقيق قراءة صحيحة لجوانب التفكير والابتكار والجمال في العمل الأدبي السردي. رواية زيبرا هي حاوية انعكاس للثقافة والمجتمع وتعبر عن الخبرات الإنسانية في شكل لغة أدبية بطلاقة ومتسامحة. يشمل أسلوب السرد؛ روايات وأفكار وأحداث، من بينها أسلوب السرد المهم للغاية؛ لأنه يشمل الفكر والحدث وهذا ما دفع بعض علماء السرد إلى قصر أسلوب

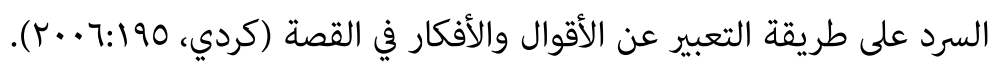

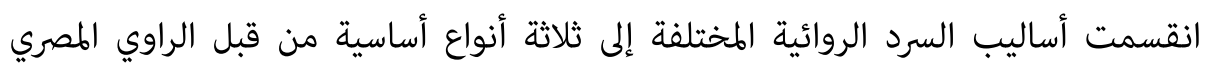
عبدالكريم كردي في كتابه (السرد فى الرواية المعاصرة)، والذي يبدو أنه طريقة مناسبة لتحليل الأساليب السردية للرواية. تتغير هذه الممارسات بناءً على دور الراوي وشخصية صاحب القول. بما أن الموقف الأساسي في القصة هو "الراوي"، لذلك، بترتيب هيمنة الراوي، تتشكل الأقوال في الأشكال الأساسية الثلاثة التالية في القصة: ا - للراوي سيطرة كاملة على السرد ولا يسمح لشخصيات القصة بالتحدث وهو ما يسمى

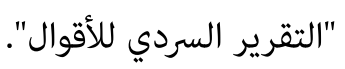

r- سيطرة الراوي ضعيفة؛ يشارك الراوي والشخصية في التعبير عن الأقوال ويظهران بثلاث طرق: الكلام غير المباشر، والكلام الحر غير المباشر، والكلام المباشر في القصة. بـ لا سيطرة للراوي، والشخصيات تعبر بحرية عن كلماتها وألفاظها، وهو ما يسمى "الكلام

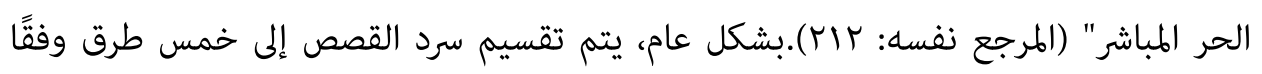

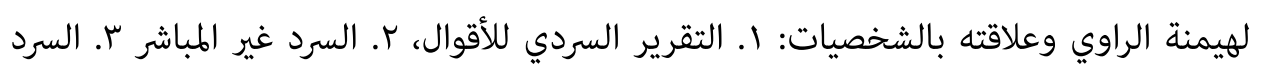

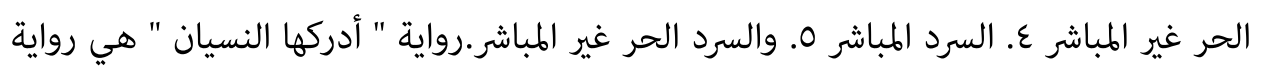
واقعية بتجارب فردية وموضوعات يختلط فيها الواقع بالشخصية والرؤى والعواطف والطشاعر.

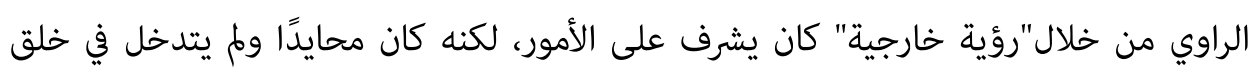
الأحداث، بل؛ يعبر عنها دون تحيز، كما يراها أو يفهمها من عقول الشخصيات، في سياق بسيط الشوريط وجميل وجذاب وقوي ومفهوم، وأحيانًا بحجة الحفاظ على الأصالة والتقاليد، يستخدم اللهجة

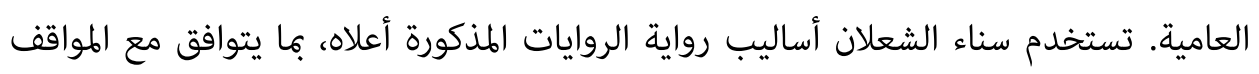


السردية، وعلاج (أدركها النسيان). هذه الأساليب هي: الإبلاغ السردي للألفاظ، وطريقة النطق المباشر، وطريقة الكلام الحر غير المباشر، وطريقة الكلام الحر المباشر، وطريقة الكلام غير المباشر. |- إ-ع- طريقة الكلام الحر المباشر

يبدأ سرد الشخصيات بهذه الطريقة دون أي مقدمة أو شرح سردي من قبل الراوي في القصة

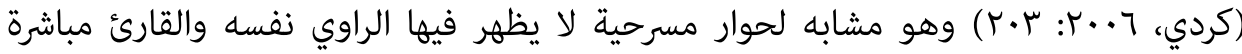
معها. يواجه الشخصيات الخيالية وأقوالهم. وبالتالي، يحتاج المستلم المخاطب إلى مزيد من الخيال ليعيش بين الشخصيات في القصة. مثل هذه الطريقة ليست شائعة في النصوص الأدبية العربية القديمة (المرجع نفسه: ع·r) وتتمثل ميزتها في المواجهة الواضحة للقارئ مع شخصيات القصة لتلقي أقوالهم دون أي وسطاء أو تفسيرات والحكم عليها. (سبعة وستون عاماً لم تسرق من شبابة ونشاطة وابتسامة الا القليل غير الماسوف عليه من ذلك فى حين اعطته هناء وخبره وتجربه والمعيه تفوق هذه السنين الطويله المزحومه بالعمل والانجاز والتطواف فى دنيا الله

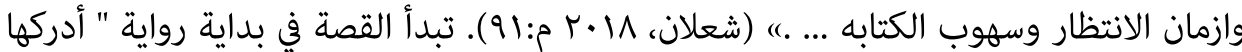
النسيان " دون أي مقدمة. (ضحاك يقول: TV سنة من العمر ما عدا القليل من الشباب مل ير الفرح والضحك في حلمه، بينها كل تلك السنوات ليست حزينة، لأنها أعطته الفرح والخبرة والخبرة والذكاء الذي تغلب على هذه سنوات طويلة وصعبة مع العمل والنجاح والسفر في عالم الله وأوقات الانتظار وسلاسة الكتابة.)

\section{r-ع- طريقة الكلام المباشر}

تعتبر هذه الطريقة من أشهر الأساليب السردية التي تستخدم أكثر في القصص القديمة

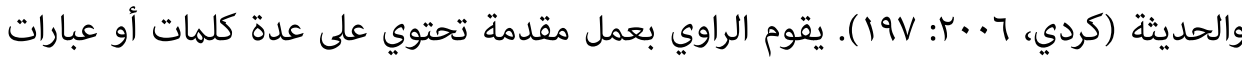
يشير فيها إلى بداية الخطاب أو طريقة تحرك المتحدث. وجاءت معظم الأقوال القرآنية كما يلي (نفس المرجع: 191). بهذه الطريقة يكون الراوي والشخصية حاضرين؛ لكن حضور الراوي أقل من الشخصية. يلاحظ الراوي هنا الثقة في السرد الكامل. هذه الطريقة مصحوبة برموز مثل [و"'"] بحيث لا تختلط كلمات الشخصية مع كلمات الراوي. ساعدت مقدمات الراوي في التعبير عن كيفية التحدث القارئ كثيرًا من أجل فهم أفضل للأقوال ولعبت دورًا مهمًا في نقل مساحة 
الكلام إليه. يبدو أن شعلان استخدمت طريقة العلاج هذه بشكل أقل. وفيما يلي أمثلة على هذا النوع: في إحدى آيات الرواية، يعبر المؤلف عن أسئلة زهاك المتكررة للجمهور، الذي يبحث عن عشيقته، بشكل جميل قدر الإمكان. "كرّر السؤال عليها أكثرمن مرّة، وسبكة فى أذنها اليمنى بتضرّع مهزوم، وعندما مل يسمع منها بنت شفه، تحول بناظريه إلى عينيها وهو يحدّق فيهما

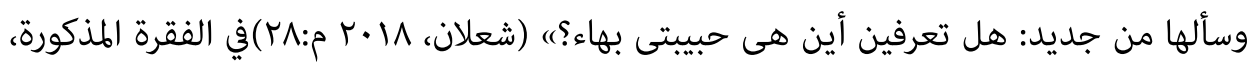
يشير وجود علامة ترقيم من نقطتين (:) ووجود ضمائر المتحدث في بعض الكلمات مثل مثلى (حبيبتى) إلى دقة الكلام. في مكان آخر من الرواية، يصور المؤلف حديث ضحاك مع التمثال بناءً على تصريحات مباشرة: " وهروباً من وضعه هذا طبع قبله سريعه على الوجنه البارده للمرأه

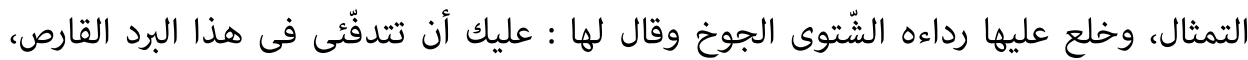
وتركها ميمّما بترنّح نحو بهو المنتجع قبل أن يسقط فى أرض السّاحة تحت المطر.)؛ (المصدرنفسه: وץ). البند مذكور في الفقرة؛ يشير وجود ضمير المخاطب إلى أن أحد الشخصيات يتحدث إلى شخص آخر. وجود عبارة مثل (عليك أن تتدفئى) دليل على وجود محادثة مباشرة. في مكان آخر من الرواية، يصور المؤلف مشهدًا تستمع فيه بهاء إلى صدى صوتها الملتف في

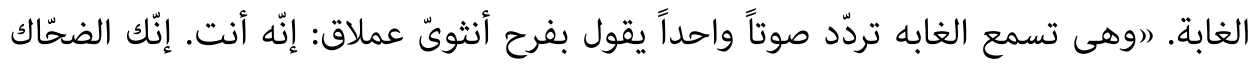

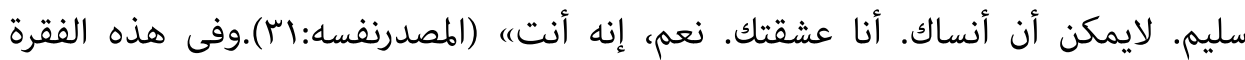
المذكورة .يشير وجود علامة ترقيم من نقطتين (:) وكذلك استخدام ضمائر منفصلة (أنا) ومتصلة في كلمة (عشقتك) إلى دقة الكلام.

\section{ع-ب- طريقة الكلام الحر غيرالمباشر}

بهذه الطريقة، يتم الجمع بين كلمات الراوي والشخصية. يمكن تييز إشارات صوت الشخصية والراوي عن الضمائر والأسماء واللهجات وما إلى ذلك. هذه الطريقة هي الوسط بين السرد المباشر والتقرير الحر وهي أكثر وضوحًا في الروايات حيث تكون الاقتباسات في العامية؛

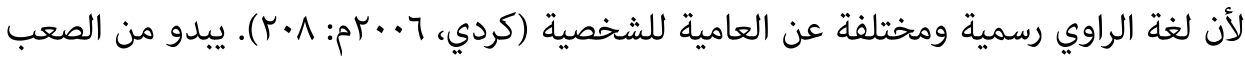
التمييز بين أساليب الإبلاغ السردية وغير المباشرة؛ لكن الانتباه إلى محتوى التقرير السردي يمنع الباحث من ارتكاب خطأ. في النسيان السادس عشر نقرأ: (لا يزعم انه ينفر منها، او انه 
يحتقرها، او يشعر بانها مدنسه قذره، بل يخفض ارضاً ويتحاشى النظر فى وجهها المحزون بعد

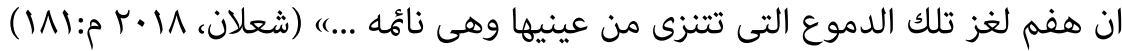
في الواقع، في هذه الفقرة من الرواية، يبدو الأمر كما لو أن أسلوب كلام الراوي وشخصيته

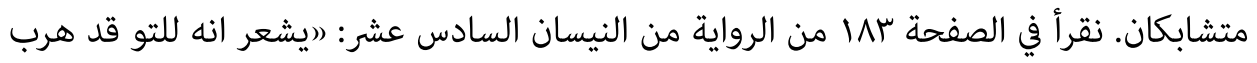
معها من الميتم وانهما ما يزالان طفلين صغيرين حاملين وان حبيبته قد نامت فى سريرها كى

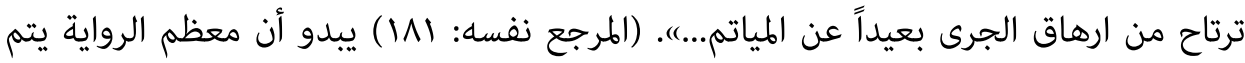
التعبير عنها بهذه الطريقة.

\section{ع-ع- طريقة الكلام غير مباشر}

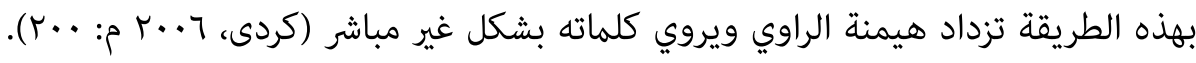
يعبر هذا الأسلوب السردي عن هيمنة الراوي في القصة. لأن حضور الشخصية في التعبير بكلماتها أقل من حضور الراوي. بهذه الطريقة، يتم تغيير ضمير المتحدث إلى ضمير الشخص الثالث في اقتباس مباشر، ويتم التعامل مع التقرير بطريقة سردية، بعبارات مثل: يتم استخدام "(قال انه)، (همس انه)، ((تحدث انه)، به جاى ("قال: انى)، ("همس: انى)،. هذا الأسلوب له حضور رائع في القصة؛ استخدم المؤلف جميع الأساليب السردية لتنويع أعماله. إن طريقة "السرد غير المباشر" قريبة من الرواية، وبعضها مذكور أدناه: "او ما يكاد يقترب القارب من ضفّه المرسى الخشبى الصغير حتّى يسارع وسيم إلى المرأه الشّقراء التى تترنّح فى وقفتها، ويمد يده إليها، فيشِدها إليه من يدها الممدوه نحوه باحتياج وثقه وترجّ وانكسار، ويأخذها إلى حضنه، ويهمس فى لى

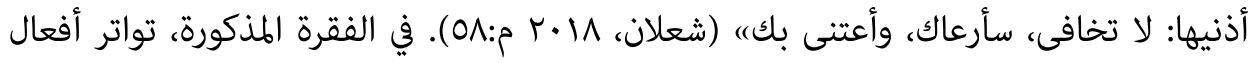
الجر بصيغة المذكر المفرد للغائب (يقترب، يسارع، تترنّح، يمدّ، يشدّ، يأخذ ويهمس) بكثرة وهذه إشارة غير مباشرة للألفاظ. وفي جزء آخر من الرواية يقول المؤلف: 》القد طلب من صديقتها هدى أن ترافقهما إلى مباس بيتهما الوطن فى مدينته الأسكندنافيّه، لكنّها رفضت ذلك، لأننّ لها حياتها الخاصه التى تنتظرها فى مدينتها حيث ينتظرها زوجها وأولادها وحفدتها، وعليها آن تعوذ إليهم) (المصدرنفسه:Y"r). في الفقرة المذكورة، يشير التكرار للأفعال السابقة بصيغ المفرد المذكر والمؤنث الغائب (طلب، 
رفضت) وكذلك الأفعال المضارعة ترافقها وتنتظرهما وينتظرها وتعود) إلى أن الكلام غير مباشر. في جميع الأفعال المذكورة؛ المرجع هو ضمير صديقة بهاء (هدى). مشهد الأطباء الذين يتحدثون مع ضحاك هو مثال آخر على التصريحات غيرالمباشرة في هذه الرواية. مشهد الأطباء الذين يتحدثون مع ضحاك هو مثال آخر على التصريحات غير المباشرة في هذه الرواية. (رفقد أخبره

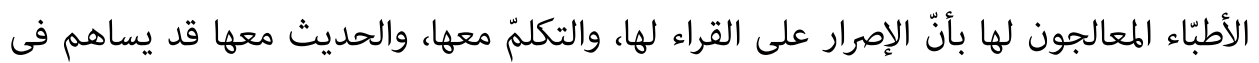
انتشالها والإنزلاق المستمر فى النسيان ويساعد فى تجمديه عند المستوى الذى وصل إليه دون

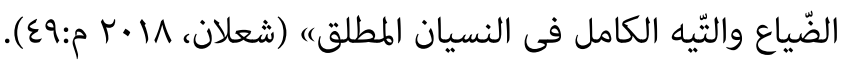
في الفقرة المذكورة، فإن وجود الأفعال الماضية والحاضرة بصيغ غائبة (أخبره، يساهم، يساعد المدان ووصل) وغياب الأفعال بصيغة المتحدث يدل على عدم مباشرة الأقوال. في جزء آخر من الرواية، يعكس مشهد رضا ضحاك عن بهاء في حياته بأي ثمن ممكن مثالًا آخر على الكلام غير المباشر.

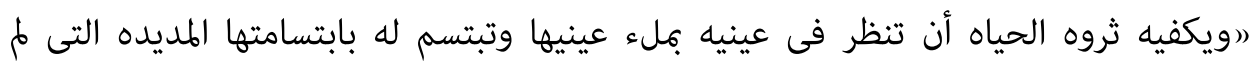
يستطع مرض السرطان أن يسرقها، وتهمس له يقين وفرح النجاه. أنت الضحّاك سليم. أنا أعرفك.

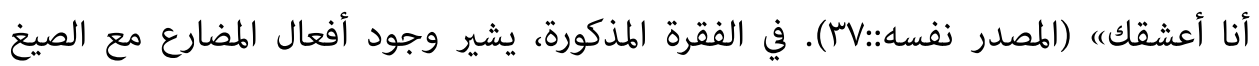
الغائبة (يكفيه، تنظر، تبتسم، لم يستطع وتهمس) إلى عدم مباشرة الكلام. في الواقع، تم اقتباس كلمات الشخصيات في شكل غير مباشر للراوي في صيغة الغائب. في جزء آخر من الرواية، يتم تقدير لحظة مونولوج ضحاك في تجسيد لحبه وهي مظهر آخر من مظاهر انعكاس التصريحات غير المباشرة. (ردّث الضحّاك نفسه قائلا: هو لا يستطيع أن يفكّر فى هذه اللحظه إلّا فى أنّه

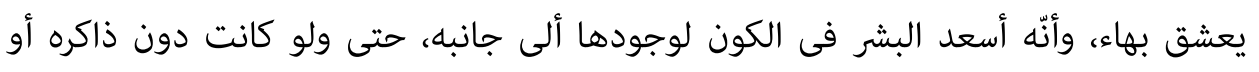

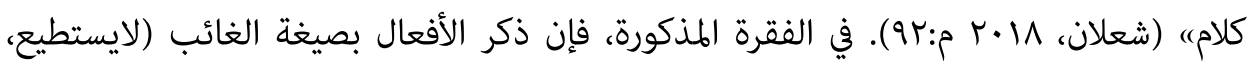
يعشق) يدل على عدم مباشرة الأقوال. إن وجود فعل مشبهه بالعفل (أنّ)، والذي هو في حد ذاته بديل مناسب للتعبيرات المباشرة، هو دليل على هذا الادعاء.

(the narrative report of speech acts) ع-0- طريقة تقرير رواية الأقوال هذه الطريقة هي جوهر السرد وأساسه حيث يتم التعبير عن كلمات وألفاظ الشخصيات بلغة وصوت الراوي. في الواقع، يُبلغ الراوي "عمل" الشخصيات؛ حتى موضوع الشخصيات 


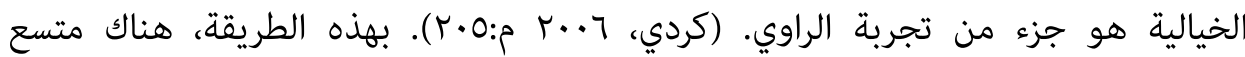

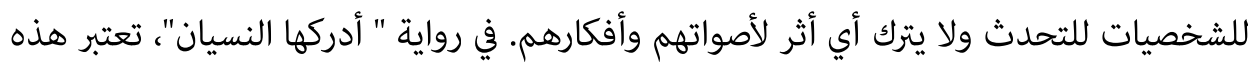
الطريقة من أكثر طرق السرد شيوعًا، ونذكر أدناه بعض الأمثلة عليها. (لابد ان بهاء كانت تحلم

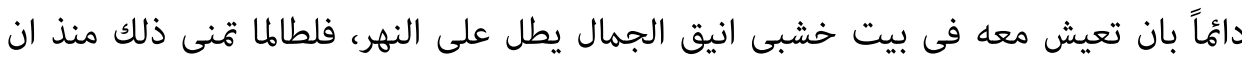

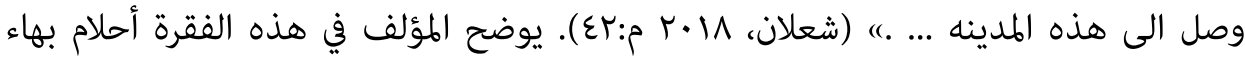
التي تتعلق بالمسائل الزوجية والحياتية بشغف وحيوية ومتعة وصفاء. في قسم آخر مذكور من هذه الرواية، يصف بداية عمل ضحاك لتجميع ونشر الرواية مع التركيز على بهاء. (القد بدا الضحاك يضع الخطوط الراويه أدركها النسيان وسوف يبدا بالتحديد من اسم بطله مخطوطه بهاء وهو اسم العاشقه) (شعلان ^1 •rم:79).في مكان آخر من الرواية، يصف المؤلف رفض

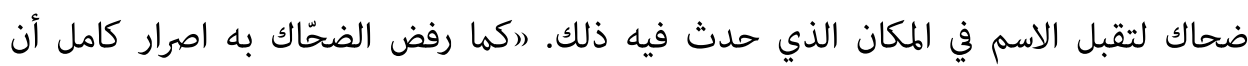
يتخلّى عن اسمه الذى اختارته له تلك الفتاه الحمراء الناريه الفاتنه التى تصغره بسنوات قليله حيث قابلها فى ميتم الشؤم الذى قضى فيه معظم طفولته الكسيره الكئيبه) (المصدر

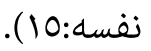
تدل الفقرة المذكورة على أن ضحاك يكره الاسم الذي اختارته عشيقته. لأن هذه كانت المرة الأولى التي يطلب فيها شيئًا يتعارض مع رغبات وأذواق عشيقته. في مكان آخر من هذه الرواية، يقترب سرد المؤلف من ذروته من الكمال والدقة؛ لأن المشهد يعبر عن محاولة ضحاك الهروب من عشيقته قدر الإمكان. (القد حاول كثيرا أن يهرّبها من الميتم، لكنّه فشل فى ذلك مرّه بعد مدرد أخرى بعد أن علمت مديرته العانس بخطّه تلك)، (المصدر نفسه:(0). في مكان آخر من الرواية، يروي المؤلف كيف اختار عائلة بهاء اسمها ويقول: (الا يعرف ما هو اسمها الحقيقى الذى وهبه الأهل المجهولون لها عندما ولدت لهم ولعلّهم لعجلتهم فى التخلّص منها ليهبودها أىّ اسم كان) (المصدر نفسه: 10-71). يوضح المقطع المعني محنة عائلة بهاء، حيث ينوون التخلص منها ونوع الاسم الذي يختارونه له؛ لا يهمهم. في الواقع؛ استطاع المؤلف أن يصور بشكل جيد معاناة 
النتائج

يتسم سرد قصة " ادركها النسيان" بلغة بليغة وبنية بسيطة وقوية ومفهومة. في ذلك، يستخدم المؤلف الأساليب والآليات السردية المناسبة لمواقف الراوي وشخصياته. راوي الرواية لديه وجهة نظر خارجية وعالة، وفي نقل الروايات السردية للقارئ، يستخدم أساليب التقارير

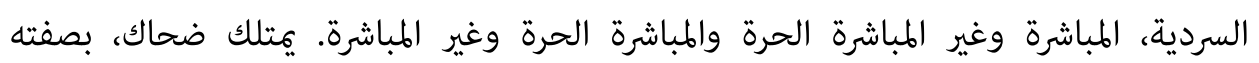
الشخصية الأولى، الكثير من الفرص لالتقاط أنفاسه والانغماس في الذكريات؛ لكن في الفقرات التالية، تأتي الشخصيات الأخرى وتتحدث مع بعضها البعض. نتيجة لذلك، يسود أسلوب الكلام

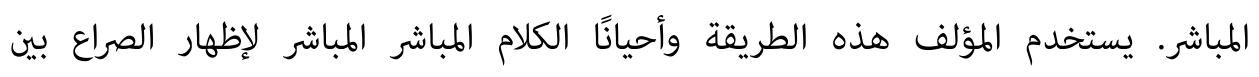
الشخصيات. رواية " أدركها النسيان" هي رواية واقعية بتجارب فردية وموضوعات يختلط فيها الواقع بالشخصية والرؤى والعواطف والطشاعر. الراوي من خلال "رؤية خارجية" كان على دراية بكل الأمور، لكنه كان محايدًا ولم يتدخل في خلق الأحداث، بل؛ يعبر عنها دون تحيز، كما يراها أو يفهمها من عقول الشخصيات، في سياق بسيط وجميل وجذاب وقوي ومفهوم، وأحيانًا بحجة الحفاظ على الأصالة والتقاليد، يستخدم اللهجة العامية. بهاء كانت تحلم دائًا بالعيش معه في في منزل خشبي جميل وفاخر يطل على النهر؛ لقد حلمت بهذا منذ وصولهت إلى هذه المدينة. يوضح المؤلف في هذه الفقرة أحلام بهاء بإمور تتعلق بالمسائل الزوجية والحياتية بشغفي النهري

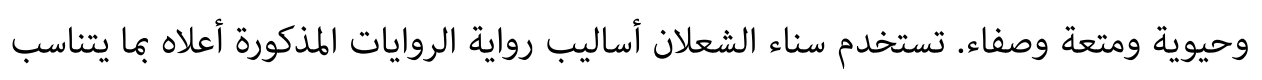
مع المواقف السردية فى رواية " أدركها النسيان".

المصادر

الحمداني، حميد، (1991 م)، بنية النص السردى من منظور النقد الأدبي، الطبعة الأولى، المركز

$$
\text { الثقافي العربي، الدار البيضاء. }
$$

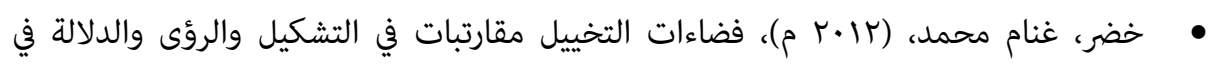
ابداع سناء اشعلان القصصي. عمان: موسسة الوراق للنشر والتوزيع. 


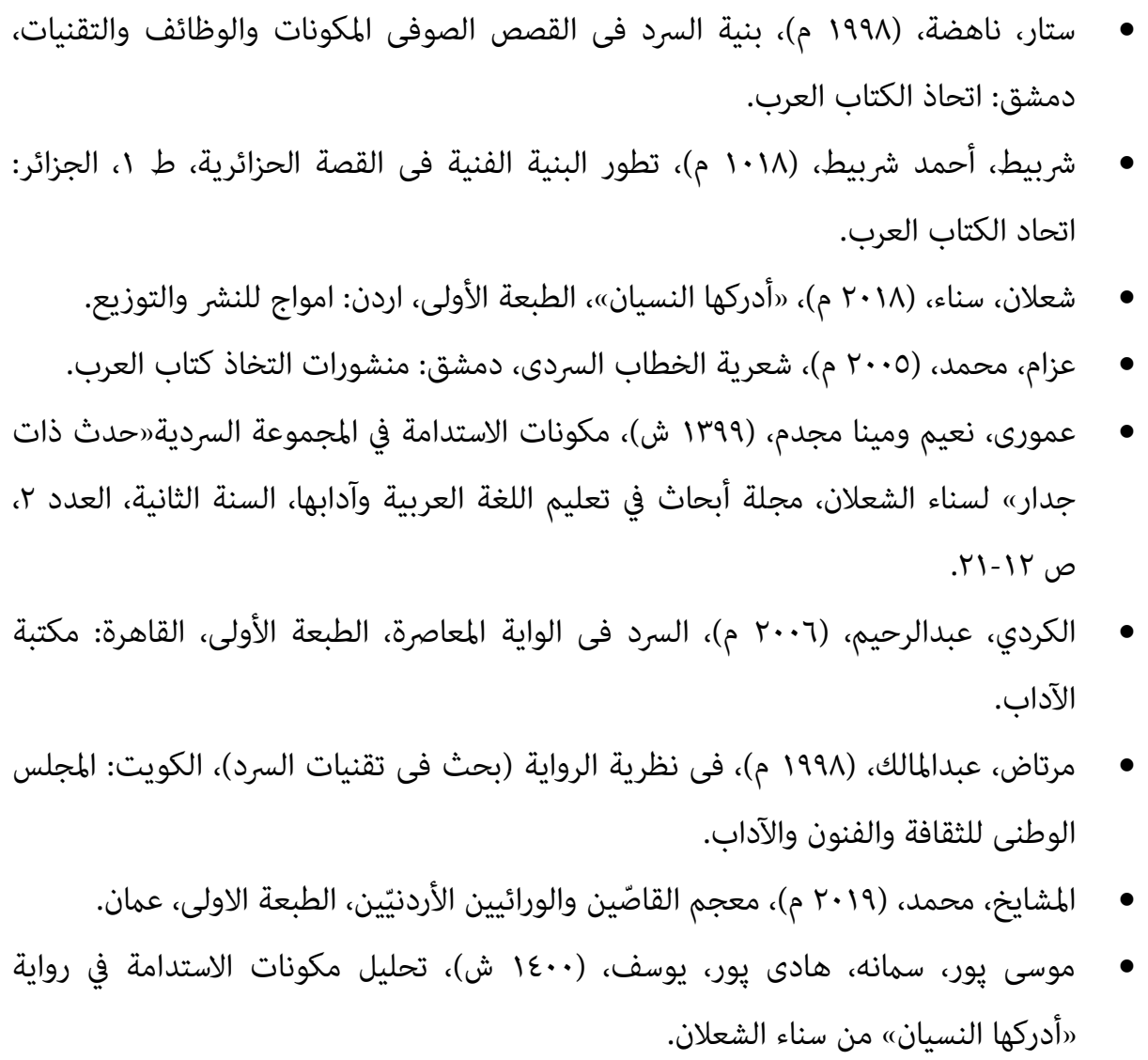

\section{References}

- Al-Hamdani, Hamid, (1991), the structure of the narrative text from the perspective of literary criticism, first edition, the Arab Cultural Center, Casablanca.

- Al-Kurdi, Abd al-Rahim, (2006), Narration in the Contemporary State, First Edition, Cairo: Al-Warraq for publication.

- Khader, Ghannam Muhammad, (2012), Spaces of Imagination, Approaches in Formation, Vision and Significance in Sanaa Ashalan's Storytelling Creativity. Amman: Al-Warraq Publishing and Distribution Corporation.

- Star, Nahdah, (1998), The Structure of Narrative in Sufi Stories, Components, Functions and Techniques, Damascus: The Union of Arab Writers.

- Sharbit, Ahmed Sharbit, (1018) The Evolution of the Artistic Structure in the Algerian Story, 1st Edition, Algeria: The Union of Arab Writers. 
- Shaalan, Sana, (2018), “Adrakha Al-nesyan”, first edition, Jordan: Amwaj for Publishing and Distribution.

- Azzam, Muhammad, (2005), The Poetry of Narrative Discourse, Publications of The Union of Arab Writers.

- Amouri, Naim and Mina Mujaddam, (2020) The components of sustainability in the narrative group "Hadath Zath Jidar" by Sanaa Al-Shaalan, Journal of Research in Teaching Arabic Language and Literature, second year, No. 2, p. 12.

- Murtad, Abdul-Malik, (1998), in the theory of the novel (research in narration techniques), Kuwait: The National Council for Culture, Arts and Letters.

- Al Mashayekh, Muhammad, (2019), The Dictionary of Jordanian Storytellers and Reveals, first edition, Oman.

- Mousa Pour, Samana, Hadi Pour, Youssef, (2021), Analysis of the components of sustainability in the novel "Adrakha Al-nesyan" by Sana Al Shaalan. 


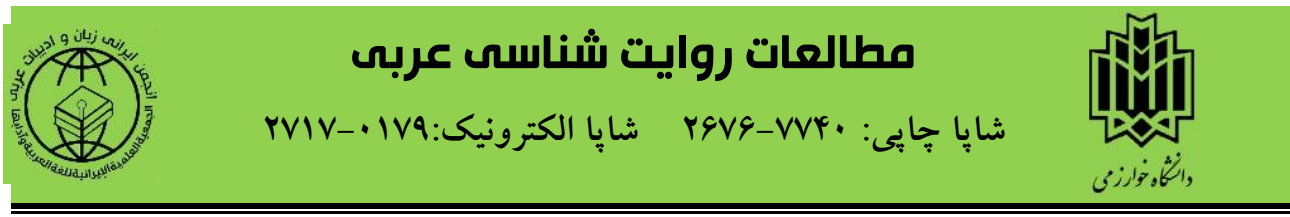

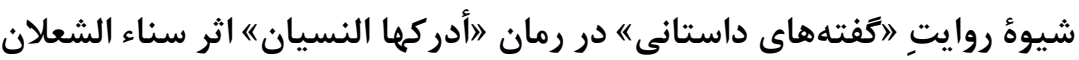
alsariyh.moosapoor@yahoo.com رايانامه: سمانه موسى :ورر دانشجوى دكترى زبان و ادبيات عربى دانشَاه آزاد اسلامى كرج، ايران. (نويسنده مسئول) hadi1339@yahoo.com رايانامه: يوسف هادى يور استاديار و هيئت علمى زبان و ادبيات عربى دانشكاه آزاد اسلامى كرج، ايران.

\section{جكيده}

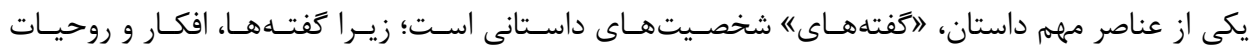

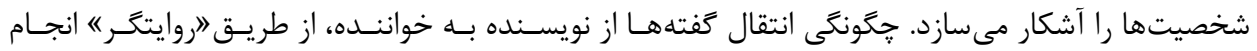

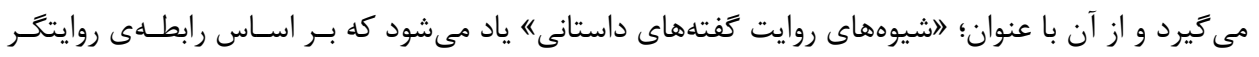

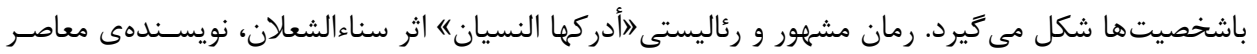

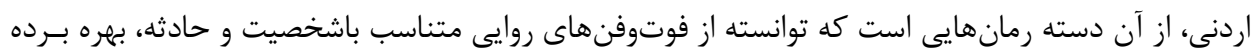

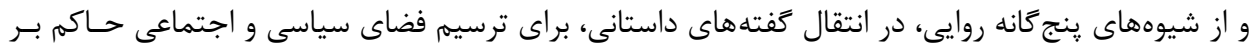

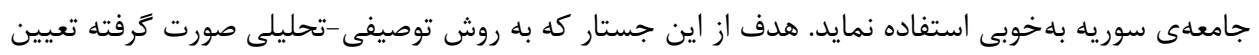

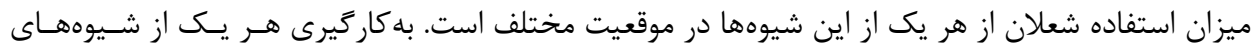

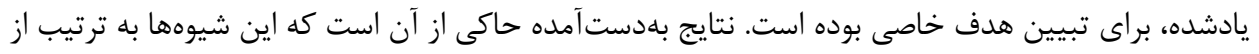

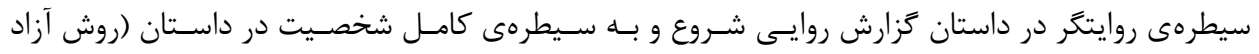

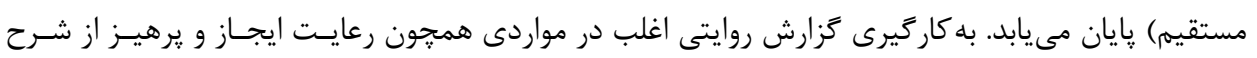

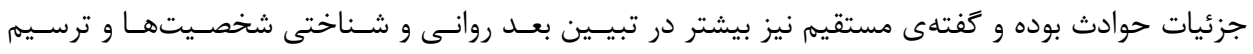

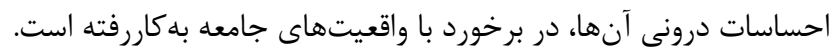

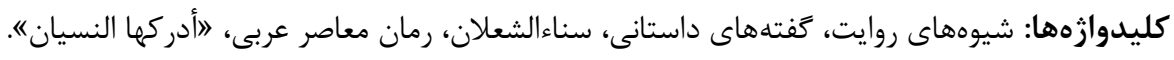

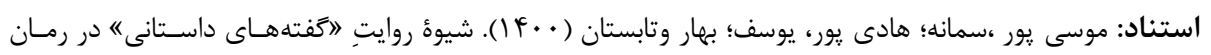

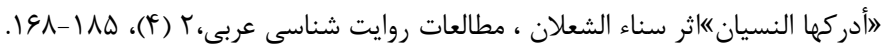

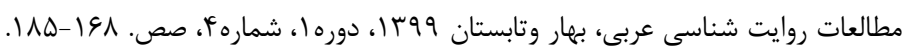

$$
\begin{aligned}
& \text { |f } \\
& \text { دريافت: أV/ }
\end{aligned}
$$


(C) دانشكده ادبيات وعلوم انسانى دانشكاه خوارزمى وانجمن ايرانى زبان وادبيات عربى 